\title{
Neuroimaging does not support the representational nature of the earliest human engravings: comment on Mellet et al.(2019).
}

\author{
Derek Hodgson
}

Mellet et al., (2019) propose that the fMRI study they employed on subjects viewing ancient engravings support the claim that such engravings were regarded as representational or "symbolic" by fossil humans. There are a number of problems with that assumption that will be examined in this commentary. First, similar neuroscans have shown that the left occipitotemporal area is activated when observers view false fonts just as much as when they view true letters. False fonts are, to a certain extent, equivalent to the examples of engravings employed by Mellet et al., except that Mellet et al., also utilised repeated cross-like motifs from Blombos that are similar to the letter X, which will have further skewed their results in favour of the left hemisphere. In fact, neuroimaging carried out by Vinkier et al., (2007) — where the raised level of activity to false fonts in the left hemisphere was apparent due to their novelty - follows a similar trajectory to that of cortical activity of Mellet et al. That is, although both the left and right hemispheres were active, the left hemisphere was more engaged for false fonts in a similar way as for engravings. Interestingly, Vinkier et al., (2007) regard the left hemisphere false font finding as resulting from elevated attentional demands. As they state: “...false-font stimuli might induce stronger attentional engagement than perceptually highly familiar real letters" (see also Nestor et al. 2013) In addition, the suggestion that the Visual Word Form Area (VWFA) is involved in processing other stimuli such as objects that Mellet et al., cite is highly controversial. Not least because one compelling line of research repeatedly demonstrates that the area deals exclusively with processing meaningful words (Dehaene et al. 2010; Gailliard et al. 2006; Nestor 2013). But, even if it were true that the VWFA processes other information, that finding would also challenge Mellet et al's findings as gratings, which are similar to the line junctions and crossings of the engravings, activate the same area (Vogel et al. 2014). It seems therefore that line 
junctions and crossings have a special status in early to mid-level visual cortex, including V1 (see for example Chang et al. 2015;Sigman et al. 2005; Szwed et al. 2012).

Secondly, based on their findings, Mellet et al., make the strong claim that the engraved patterns were potentially employed to store and transmit coded information and may be representational. Such a claim appears unwarranted given the above critique. There is no doubt that the engraved patterns demonstrate a measure of structure but this is because it reflects the underlying heuristics as to how the visual world is configured and perceived as such. Correspondingly, present day scripts universally employ a restricted number of similar but implicit configurations in the form of end-stopped lines, junctions, and crossings, which were employed unbeknown to the originators of those scripts (Changizi et al. 2006). That is because, as neuroscience has revealed, much of the neural processing occurs preconsciously in a way that biases behaviour (King et al. 2016; Price and Devlin 2011; Gaillard et al. 2006).

Thirdly, with regard to the Hodgson's (2006) Neurovisual Resonance Theory, Mellet et al., state that in previous publications I suggest that the primary visual cortex or V1 constitutes the unique area of the cortex that can explain how the first engravings arose when I specifically stressed that V1 is part of a hierarchical system that includes V2, V4, LOC. In addition, I also allude to the role of the occipitotemporal area involving feedforward and feedback neural loops (see Hodgson 2006, 2008; see also Price and Joseph 2011 as well as Chang 2015 on neural loops).

According to the Neurovisual Resonance Theory, the reason repeated lines and geometric shapes were so appealing to hominins is because they are an integral and fundamental feature of the visual brain. By producing such patterns the underlying neural heuristics were stimulated leading to neural resonance that induced pleasure leading to a repetition of the procedure. 


\section{References}

Chang, C.H.C., Pallier, C., Wu, D.H., Nakamura, K., Jobert, A., Kuo, W.-J., Dehaene, S. 2015. Adaptation of the human visual system to the statistics of letters and line configurations. Neuroimage. https://doi.org/10.1016/j.neuroimage.2015.07.028.

Changizi, M.A., Zhang, Q., Ye, H. and Shimojo, S. 2006. The structures of letters and symbols throughout human history are selected to match those found in objects in natural scenes. The American Naturalist. 167( 5) https://doi.org/10.1086/502806

Dehaene, S., Pegado, F., Braga, L.W., Ventura, P., Nunes Filho, G., Jobert, A., Dehaene-Lambertz, G., Kolinsky, R., Morais, J., Cohen, L., 2010. How learning to read changes the cortical networks for vision and language. Science. 330. 1359-1364.

Gaillard, R., Naccache,L., Pinel, P., Clémenceau, S., Volle, E., Hasboun, D., Dupont, S., Baulac,M., Dehaene, S., Adam,C. and Cohen, L. 2006. Direct Intracranial, fMRI, and Lesion Evidence for the Causal Role of Left Inferotemporal Cortex in Reading. Neuron. 50: 191-204,

Hodgson, D. 2006. Understanding the Origins of Palaeoart: The Neurovisual Resonance Theory and Brain Functioning. Paleoanthropology http://paleoanthro.org/journal/2006/

Hodgson, D. 2008. Neurovisual theory, the visuo-motor system and Pleistocene palaeoart. (Paper presented at UISPP XV International world congress in Lisbon, Portugal 2006). In, Pleistocene Palaeoart of the World. R. G. Bednarik and D. Hodgson (eds.). pp.49-55. BAR International Series 1804. Archaeopress: Oxford.

King, J-R., Pescetelli, N. and Dehaene, S. 2016. Brain Mechanisms Underlying the Brief Maintenance of Seen and Unseen Sensory Information. Neuron. 92:1122-1134. 
Mellet. E., Salagnon, M, Majkic’', A,, Cremona, S., Joliot, M., Jobard, G., Mazoyer, B., Tzourio Mazoyer, N. and d'Errico F. 2019 Neuroimaging supports the representational nature of the earliest human engravings. Royal Society Open Science. 6: 190086. http://dx.doi.org/10.1098/rsos.190086

Nestor, A., Behrmann, M. and Plaut, D. C. 2013.The Neural Basis of Visual Word Form Processing: A Multivariate Investigation. Cerebral Cortex. 23:1673-1684.

Price, C. J. and Devlin, J. T. 2011. The Interactive Account of ventral occipitotemporal contributions to reading. Trends in Cognitive Sciences. 15: 246-253.

Sigman, M., Pan, H., Yang, Y., Stern, E., Silbersweig, D. and Gilbert, C.D. 2005. Top-down reorganization of activity in the visual pathway after learning a shape identification task. Neuron. 46 (5): 823-835.

Szwed, M., Ventura, P., Querido, L., Cohen, L. and Dehaene, S. 2012. Reading acquisition enhances an early visual process of contour integration. Developmental Science. 15 (1): 139-149.

Vinckier, F., Dehaene, S., Jobert, A., Dubus, J. P., Sigman, M. and Cohen, L. 2007. Hierarchical Coding of Letter Strings in the Ventral Stream: Dissecting the Inner Organization of the Visual WordForm System. Neuron. 55: 143-156.

Vogel, A. C., Petersen, S. E., and Schlaggar, B.L. 2014. The VWFA: it's not just for words anymore. Frontiers in Human Neuroscience. doi.org/10.3389/fnhum.2014.00088 